\title{
Crimequest, A CLIL Approach of "Learning on Gaming" to Improve Science Education and Language Learning
}

\author{
Immacolata Ercolino \\ PhD Candidate School of Life and Health Science. \\ Molecular Biology and Cellular Biotechnology, \\ University of Camerino (MC), Italy \\ Sabina Maraffi \\ $\mathrm{PhD}$ candidate School of Science and Technology, \\ Geology Division, University of Camerino (MC), Italy \\ Francesco Maria Sacerdoti \\ e-voluzione s.r.1., Italy
}

Doi: 10.19044/esj.2018.c5p17 ～URL:http://dx.doi.org/10.19044/esj.2018.c5p17

\begin{abstract}
This work focuses on Science teachinginhigh school using the Content and Language Integrated Learning (CLIL) approach. Students need to be educated as science active citizensso that to be able to close the skills gap between science literacy and societal requirements. In fact it is important to combat misconceptions in order to face challenges that daily involve society and request skills and knowledge in science. Teachers need new insights to foster youngsters learning and to enhance digital literacy and competences and need to update them continuously. The authors have realized a role playing computer game called CrimeQuest with a specific Role Playing Engine, which involves all students into the adventure through their personal mobiles or tablets, with a complete interaction of the whole class with the game. The students interact with the system using their own smartphones and tablets with a new technology, which collects the individual answers. At the same time the system calculates the overall response according to the criterion of majority voting. The game works without Internet and is realized with a specific software engine that interprets a text file as the adventure plot, with text-to speech multi-language voices. Learning on gaming through our Computer Class Role Playing Game is a way to realize "authentic learning": it lets students feel themselves on a Crime Scene, involving them in their own learning. In this way foreign language becomes a vehicular tool to discover new topics and their specific
\end{abstract}


glossary: it is a CLIL approach, in which the not language subject is taught through a foreign language.

Keywords: Learning on Gaming, CLIL, Science Education, Forensic Science, CALL

\section{Introduction:define CLIL}

Foreign languages are essential to ensuring that European citizens can move, work, and learn freely throughout Europe. This will help boost jobs and growth, reducing unemployment and increasing living standard (European Commission 2014). Education is central to developing the capabilities required to expand the opportunities people need to lead meaningful lives in equal dignity. A renewed vision of education should include developing critical thinking, independent judgment and debate (UNESCO 2015). Education is a sort of equalizer, never as important as today. European countries have developed strategies and plans that focus on different ways to increase the efficiency and effectiveness of foreign language education in schools. Content and Language Integrated Learning (CLIL) is a competence-based teaching approach that has been growing over the last ten years and is expanding quickly across the European education systems and beyond. It is an approach to teach the content of curricular subjects through the medium of a non - native language. In a CLIL course, learners gain knowledge and understand the curricular subjects while simultaneously learning and using a target language. We can define CLIL as "an educational approach in which a foreign language is used as the medium of instruction to teach content subjects for mainstream students" (Nikula T., et al, 2013). CLIL is an integrated approach to content and language (Lasagabaster D., 2008). It integrates content and language by learning a content subject through the medium of a foreign language and by learning a foreign language through studying a content-based subject (Ruiz de Zarobe, Y.R.,, 2008). CLIL methodology, as CBI (Content Based Instruction), helps students to learn better: CBI-CLIL offers models, curricular variations and a continuum which highlights the fact that institutions may opt for content-driven as well as language-driven implementations. Science and technology education in schools has traditionally served an elite group of students (Driver, R., Leach, J., Millar, R., \& Scott, P, 2005; Fensham, P.J., 1992). "Traditional school science teaching attempts to socialize students into a scientific way of thinking and believing "(Aikenhead G.S., 2005). Very often traditional science lessons result decontextualized not connected to real life and then boring. Moreover, the opportunity to find new engaging learning environments is very intriguing for learners, while classroom teaching propose often the same traditional educational setting. "This social 
need gave rise to the science-technology-society (STS) movement in science education"(Aikenhead, G.S., 1994). Nowadays students need to understand the interactions between science \& technology and their society. Teachers know that motivation is one of the most important factors to enhance student learning. Teachers are key players in the renewal of science education..

According to $21^{\text {st }}$ Century Directions: The main recommended approach to teaching key competences is through the provision of interactive learning environments in which learners can engage in practical, inquirybased tasks. These environments present open-ended problem and challenges to be solved through debate, experimentation, exploration and creativity.

"Among other methods, being part of a network allows teachers to improve the quality of their teaching and supports their motivation" (Rocard M., et al., 2007).

CLIL works with meaningful, challenging and authentic context that can motivate learners much more than traditional approach. Real world contexts engage students because they provide suitable learning environments for problem-based learning. CLIL scaffolding reinforces students' learning. They need scaffolding (Böttger, H., Meyer O., 2008) in order to improve language. Scaffolding is a powerful teaching tool; in fact facilitates students in understanding the content and the language in the task and enables learners to complete exercises by providing correct supportive structures. Scaffolding, besides, supports the enrichment of specific vocabulary and entire phrase construction by providing motivation, enthusiasm and language proficiency enhancing skills. It promotes the interaction between learners that begins to communicate with each other in an authentic way, stimulating thinking skills together with a specific topic glossary. The resulting outputs consist in enhancing fluency in communication and in increasing self esteem.

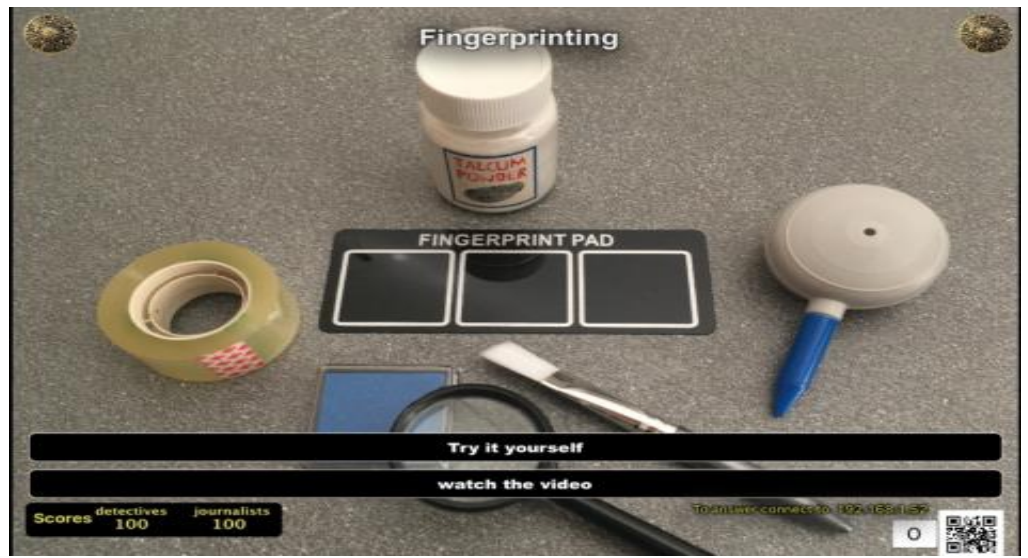

Figure1: Screenshot of one CrimeQuest page regarding a hands on activities ( fingerprint detection). 


\section{CALL (Computer Assisted Language Learning)}

"We live in an increasingly connected world"(Brito Vieira, M. \& Runciman, D., Representation, 2013) with new technologies and social networks. Strengthening education systems, joining innovation and creativity with technologies aimed at young students can enhance European students' full potential. "Digital technologies are an inseparable part of today's learning process. The European Commission works on several policy initiatives in order to modernise education and training, provides funding for research and innovation in order to promote digital technologies used for learning and measures the progress on digitization of schools"( Digital Learning \& ICT in Education, European Commission 2018) According with the Digital Agenda, many European countries have realized significant investments in order to ensure universal access to ICT, particularly to help tailoring the use of technology in the education process to improve digital skills. A large majority of headmasters and teachers agree with the positive impact of Information and Communication Technology (ICT) use in learning environments and students' motivation. An overwhelming majority of students is also positive about the impact of ICT on the classroom atmosphere and on different learning processes.

Computer assisted language learning (CALL) refers to any process in which the learner uses a computer to improve foreign language competence. The involved technology includes not only computers but also smartphones, tablets, MP3 players, and consoles. A large number of studies confirm that learners enjoy using technology in foreign language learning and that they prefer using technology over more traditional methods and materials (European Commission 2014).

\section{Methodology}

We created an innovative methodology based on the game, that enhances the interdisciplinarity, the information retrieving and decoding, for all school levels. The Computer Class Role Playing Game (Fig.1) is a new technology designed for deeper learning of Biology, Earth Sciences, Chemistry, Environmental Sciences, by improving the innovation and creative capacities of learners and by supporting the new role of teacher as a learner's coach. Our game uses EVO-RPGE (Role Playing Game Engine), a new engine (Sacerdoti F.M. \& Maraffi. S.,, 2015) developed to easily build interactive role-playing games, which involve all students who participate in the game through their own mobile or tablet (Fig.2), giving a global interaction of the class within the game. The game can be followed by the whole class with a IWB (Interactive White Board) or a projector (Fig.3). 


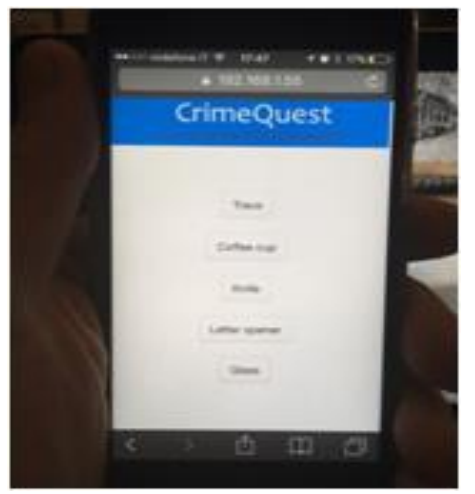

Figure 2: Screenshot of

CrimeQuest on a smartphone

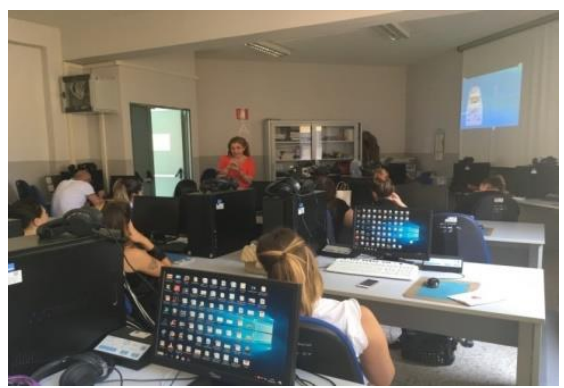

Figure 3 A whole class following the game with an IWB

The game can be played in a laboratory to accomplish one or more hands-on activities or in a classroom simulating a workshop activity.

Texts are spoken by a high quality synthesized computer voice in several different languages, so it is perfect for CLIL compliance.

Teachers can create their own "adventure" writing a text file enriched with texts, image names, questions, jumps, fostering students' curiosity in their learning etc. The system is multi-language allowing different text files one for each idiom.

\section{CrimeQuest}

In CrimeQuest we take advanced of storytelling (see an example of story setting in Fig.4), which is a powerful tool to foster students' curiosity and to improve learning. Our game is interactive: we bring all the participants (or our students in a class) on a virtual crime scene in a lab. In the story, a researcher is found dead in a research lab: was it an accident or a suicide or a murder? "Who killed Prof. Maya Foster?". The students must solve forensic logic problems and they are involved in many hands-on activities with "poor materials": DNA profiling, digital fingerprints, hair comparison, analysis of sticky soil on killer's shoes (players will compare different kinds of soil with an Earth Science hands-on Lab) and Luminol test on the crime scene. Students collect all the clues and the bodies of evidence on the Crime Scene and can have free access to materialsthat they found 
along the way, including original texts created on purpose, as a note-book about Biotechnology. Materials consultation is easy and immediate, since they are realized as synthetic PowerPoint presentations or PDF files rich of icons and pictures (Ercolino I., Maraffi S., Sacerdoti F.M,, 20016). Students can check their personal score, related to their role in the game, on their devices. In fact, players can choose a different "role" in the game: scientist or journalist. The system gives distinct scores to each group based on the "weight" each question has for the different roles played by participants. The progression of the game can be followed by students with different levels of knowledge and skills using the note-book as compensatory measure. The iconographic contributions, the use of different communication codes (visual and auditory) and the structuring of the questions are ideal for a personalized teaching, even in the case of Special Education Needs.

\section{Conclusion}

We presented CrimeQuest at Science on Stage festival 2017 and tested it with some high school classes: at present we are analyzing the experimentation results. The observation in the classrooms during the game gave very good results: students were interested and participated for the entire duration of the activity (Fig.5).In fact, the game is an activity aimed at promoting the development of everybody's personality, especially in the perspective of learning to learn (Key Skills) (Maraffi, S. \& Sacerdoti,, 2017). We observed that CrimeQuest Game reallyengaged students in their learning. Our future goal is to experiment again the combination of CLIL and CALL with new method logical and pedagogical tools for implementing CLIL in bilingual education and for assisting teachers as well, in their own storytelling design, by supporting teachers to express their creativity and provide them with an adequate setting for CALL integration. Therefore we strongly advice the development of this type of CLIL tools combining a technological component.

"Life is increasingly non-routine, problem-based and technology rich. That's why education systems are moving away from solely content-led approaches, and focusing more on helping learners develop a range of competences to cope in our complex world. Education today, just as in previous centuries, is intended to promote learners' personal growth, citizenship and preparation for the world of work." (Smith, M.K., 2005).

CrimeQuest is an innovative teaching tool developed according to this vision and, through testing, has proved effective in facilitating learning with a competence-based approach. 


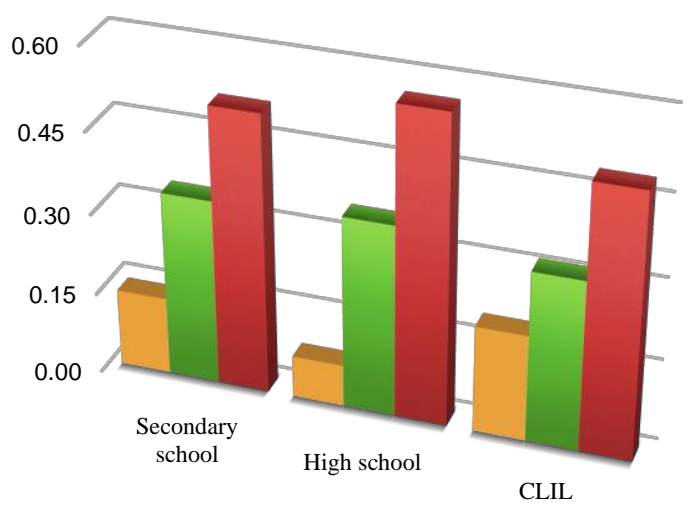

Fig. 5. Efficacy of interactive methodologies, also in case of CLIL methodologies (Content and Learning Integrated Learning), compared with Traditional and PPT lessons.

\section{References:}

1. Aikenhead G.S. Research into STS Science Education. Published in Educacìon Quìmica, 16,384-397. 2005.

2. Aikenhead, G.S. What is STS science teaching? In: Solomon, J. and Aikenhead, G.S. Ed.,STS Education International Perspectives on Reform, Teacher's College Press, New York. 1994.

3. Böttger, H., Meyer O. Materials for bilingual teaching Interdisciplinary materials: 5./6.School Year - Going CLIL - Prep Course: workbook (English)Paperback - Cornelsen. 2008.

4. Brito Vieira, M. \& Runciman, D., Representation. ISBN: 978-07456-5829-2. Wiley. 2013.

5. CrimeQuest

Video

demo

:https://www.youtube.com/watch?v=mmsdb1tRJ-cAt

link: https://www.youtube.com/watch?v=vzZITsJdL1A is available a video reporting an interview on Superquark (Italian television). 2017.

6. Driver, R., Leach, J., Millar, R., \& Scott, P. Young people's images of science. Buckingham: Open University Press. 1996.

7. Ercolino I., Maraffi S., Sacerdoti F.M. Could smartphone in science teaching foster motivation and positive attitudes in students? International Conference New Perspectives in Science Education,New Perspectives in Science Education International Conference Proceedings, ISBN 9788862927055, 127-131. 2016.

8. European Commission 2014. Supporting education and training in Europe and beyond Languages in education. 2014. 
9. Digital Learning \& ICT in Education 2018

10. Fensham, P.J. Science and technology. In P.W. Jackson (Ed.), Handbook of research on curriculum. New York: Macmillan Publishing Co., pp. 789-829. 1992.

11. Lasagabaster D. The Open Applied Linguistics Journal, 1, 31-42, 2008.

12. Maraffi, S. \& Sacerdoti, F.M. "Learning on Gaming" Improves Science Learning in a STEAM Interdisciplinary Approach. Journal of Environmental Science and Engineering A 6 (2017) 155-165 D doi:10.17265/2162-5298/2017.03.007. 2017.

13. Nikula T., et al. CLIL classroom discourse. Journal of Immersion \& Content-Based Language Education 1, 70-100. 2013.

14. Rocard M., et al. Science Education Now: A renewed Pedagogy for the Future of Europe, ISBN - 978-92-79-05659-8 ISSN 1018-5593. European Communities, 2007.

15. Ruiz de Zarobe, Y.R., CLIL and Foreign Language Learning: A Longitudinal Study in the Basque Country. International CLIL Research Journal 1. 2008.

16. Sacerdoti F.M. \& Maraffi. S. EVO-RPGE an Interactive Role Playing engine. ICEILT - The International Congress on Education, Innovation and Learning Technologies, Granada, 2015. ISBN: 97884-944311-3-5. Edited by: Science KNOW Conferences C.B. September 2015, p.148. 2015.

17. Scott,D., Beadle, S. Improving the effectiveness of language learning: CLIL and computer assisted language learning. pp. 19 - 22. European Commission. 2014.

18. Smith, M. K. 'Competence and competencies', the encyclopaedia of informal education. Sweden. 2005.

19. UNESCO. Rethinking Education. Towards a global common good? ISBN 978-92-3-100088-1. 2015 